\title{
Experimental Study on Coupled Cooling System of PCM-Heat Pipe for Vehicle Power Battery Pack
}

\author{
H.B. Chen \\ State Key Laboratory of Automotive Simulation and Control \\ Jilin University \\ P. R. China \\ Department of Thermal Engineering \\ Jilin University \\ P. R. China \\ H.X. Li \\ State Key Laboratory of Automotive Simulation and Control \\ Jilin University \\ P. R. China \\ X.F. Liu \\ State Key Laboratory of Automotive Simulation and Control \\ Jilin University \\ P. R. China
}

\begin{abstract}
With the problem of environmental pollution and energy shortage is becoming increasingly serious, researches on electric vehicle (EV) are getting more and more attention. As an important energy source of $\mathrm{EV}$, the working status of power battery will affect the performance of the vehicle. The performance and lifespan of battery is tied up with its temperature distribution. In this paper, experiment bench is established to study the impact of heat pipe on the temperature distribution in the battery pack. As to the experiment bench, ten electric heating plates are used to imitate the power batteries in the pack, and the heat of battery pack is soaked up by the composite phase change materials (PCM) of paraffin and graphite, and the heat is transferred outside by four heat pipes. The research shows that it has positive cooling effect on the battery pack to adopt PCM-heat pipe coupled system, which can basically ensure the battery is operating within the best temperature range. Compared with the pure PCM system, the using of heat pipes can reduce the temperature rise of the battery up to $10{ }^{\circ} \mathrm{C}$. Meanwhile, the temperature distribution of PCM-heat pipe coupled system is more uniform than the system without heat pipes, which avoids having a negative effect on the performance and lifespan of the battery.
\end{abstract}

Keywords-power battery; heat pipe; cooling; experiment

\section{INTRODUCTION}

Peopled are forced to seek alternative energy sources because fossil fuel resources tend to be exhausted. In the recent ten years, enormous human resources and financial funds have been invested to the research on new energy vehicles by the world's leading automotive companies and research institutions. Because of the outstanding advantages of electricity, the research and development of EV has been the mainstream of developing environmentally-friendly vehicles

\author{
H.Z. Cao \\ State Key Laboratory of Automotive Simulation and Control \\ Jilin University \\ P. R. China \\ X.W. Zhao \\ State Key Laboratory of Automotive Simulation and Control \\ Jilin University \\ P. R. China
}

all over the world [1, 2]. Research results show that if the use rate of hybrid electric vehicle (HEV) reaches 50 percent, 14 percent energy consumption will be saved[3]. Moreover, compared with traditional fuel cars, the greenhouse gas emissions of EV reduce about 35 percent [4]. However, when charging and discharging the power battery, the higher magnification it uses, the higher temperature rises of battery. Research shows that if the temperature rises $5^{\circ} \mathrm{C}$, the lifespan of battery will be halved [5].Through the survey on electric buses in Changchun city public transportation conducted by the authors, it can be found that those electric buses are cooled by air flow from surroundings, whose structure is rough and the seal is not effective that it may cause rainwater infiltrate into the battery pack. If the filter is set on the air vents, the flux of air flow through the batteries will drop down, not leading the prompt dissipation of heat. In order to achieve better cooling effect, this paper explores the cooling effect of PCM-heat pipe coupled system and prove the advantages and feasibility of the coupled system in EVs.

\section{EXPERIMENTAL PROJECT}

\section{A. Experimental Equipment and Materials}

In this experiment, electric heating plates are used to imitate power batteries in the pack, and the composite PCM, which is made up of paraffin and graphite (mass ratio is 4:1), is filled the space between electric heating plates. The heat generated is transferred outside by four heat pipes, which are inserted into PCM to cool the battery pack. The kinds parameters of experimental equipment used are shown in Table 1. 
TABLE I. EXPERIMENTAL EQUIPMENT USED IN THIS STUDY.

\begin{tabular}{|c|c|}
\hline Experimental equipment & Remark \\
\hline Heat pipe & Made by Yokogawa company. \\
\hline Multi-recorder MV200 & Kunlun semi-refined paraffin wax \\
\hline Electric heating plate & $96 * 20 * 58 \mathrm{~mm}$, and internal resistance is $250 \Omega$ \\
\hline Paraffin & $7782-42-5$, Huadong reagent plant in Tianjin \\
\hline Graphite & Nickel-chromium nickel-silicon thermocouple \\
\hline $\begin{array}{c}\text { Electric voltage } \\
\text { transformer }\end{array}$ & \\
\hline
\end{tabular}

\section{B. Heat Pipe Structure}

According to the heat transfer principle of heat pipe, the evaporation side absorbs the heat transferred from electric plates to phase change material, and transfers the heat to the condensation side by working fluid transport ability. The working fluid has phase change ability and continuously pass the heat generated by the battery into the ambient air [6], so as to achieve the heat transportation and the decrease of cell temperature. The evaporation side and condensation side of the heat pipe used in this experiment is $8 \mathrm{~cm}$ long, the tube diameter is $15 \mathrm{~mm}$, and the internal working fluid is water. The 3D model of heat pipe is shown in Figure 1.

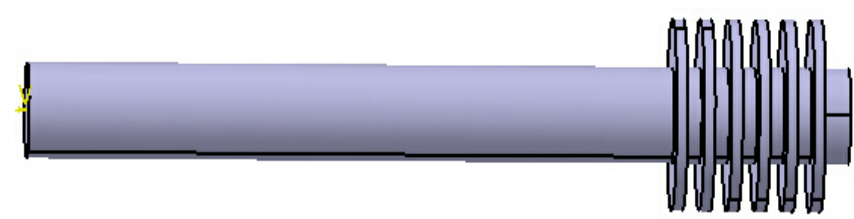

FIGURE I. THE MODEL OF HEAT PIPE USED IN THIS STUDY.

\section{The Introduction about Experiment Platform}

The experiment used electric heating plates instead of single cell. Nine pieces of electric heating plates were connected by the wires and fixed in the organic glass box to simulate power battery pack. Composite PCM made by paraffin and graphite in the ratio of 4:1 was filled in the space between the electric heating plates; the physical parameters of composite material could be referred to in relevant literature[7], and four heat pipes were inserted between the electric heating plates to help diffuse battery heat. At the same time, 10 nickel-chromium nickel-silicon thermocouples were arranged inside the battery pack for monitoring the interior temperature. The experiment bench was capable of switching different voltages at the two ends of electric heating plates in order to simulate the real working conditions of the batteries. Through analysis on the temperature changes of the battery pack under different working conditions, the experiment can explore the cooling effect of heat pipes in the battery pack. The schematic diagram of batteries is shown in Figure 2 and the photo of the pack is shown in Figure 3.

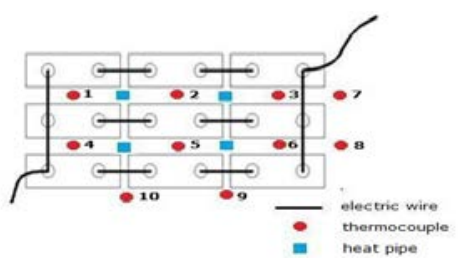

FIGURE II. SCHEMATIC DIAGRAM OF BATTERIES.

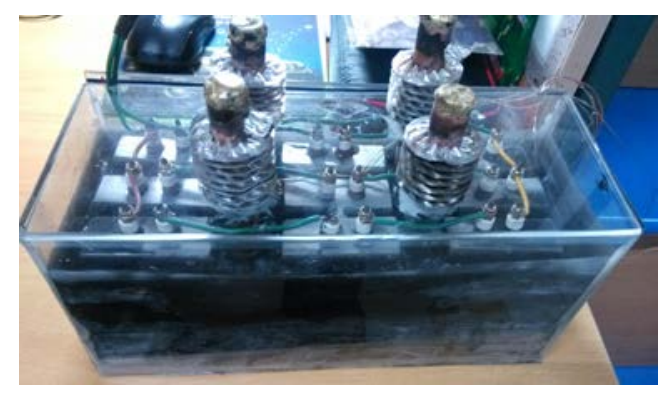

FIGURE III. THE PHOTO OF THE PACK.

\section{IIIEXPERIMENTAL RESULTS AND ANALYSIS}

\section{A. Comparison with Coupled Cooling System and Other Cooling Systems}

Heating voltage in this experiment was $75 \mathrm{~V}$, the heat release rate of cell is $2.5 \mathrm{~W}$ according to the calculation. For air cooling experiment, PCM and heat pipes were not contained in the battery pack. The data were recorded every 5 minutes since the electricity was charged in the battery. A total of 15 sets of data were recorded. The experimental procedures of pure PCM, PCM- heat pipe coupled system were as same with that of the air cooling experiment. The comparison diagram of measured points' average temperature is shown in Figure 4. Figure 5 shows the temperature distributions of air cooling system and coupled cooling system under the voltage of $75 \mathrm{~V}$ and 50 minutes after batteries was charged.

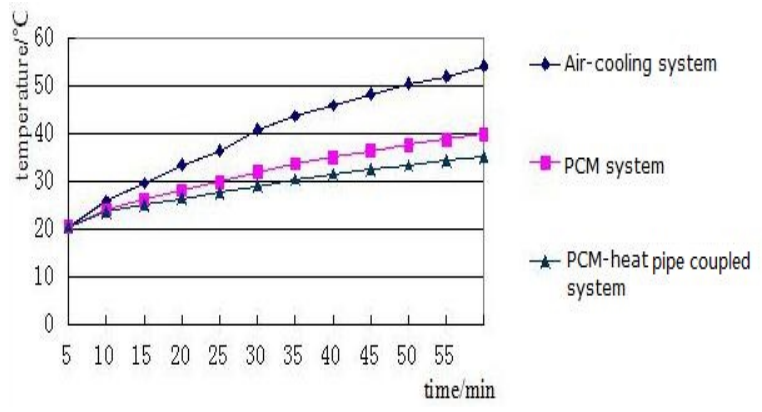

FIGURE IV. THE COMPARISON DIAGRAM OF AVERAGE TEMPERATURE IN DIFFERENT COOLING SYSTEM. 


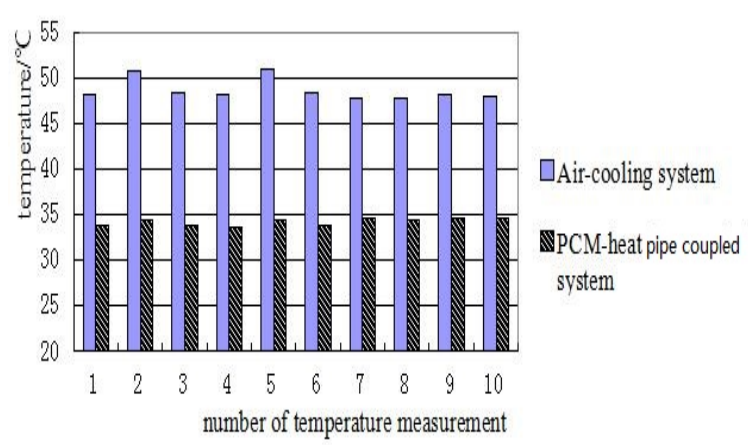

FIGURE V. TEMPERATURE DISTRIBUTIONS OF AIR COOLING SYSTEM AND COUPLED COOLING SYSTEM.

Figure 4 shows that the heat dissipation effects of PCM-heat pipe coupled system is better than air cooling system, while the pure PCM system is the middle on among these three modes. At the same time, the speed of temperature rise in PCM-heat pipe coupled system is slower than that of air cooling system under the same heat release power. From Figure 5, we can see the temperature distribution of PCM-heat pipe coupled system is more uniform than air cooling system, which effectively avoids the damage of battery performance and shortening of battery lifespan. From the above analysis, it is concluded that the cooling effect of phase change materials is better than air cooling system.

\section{B. Comparison on Thermal Properties with PCM and Coupled System under Different Conditions}

Working conditions selected in this part were $75 \mathrm{~V}, 100 \mathrm{~V}$, $125 \mathrm{~V}, 175 \mathrm{~V}$ (heat release values of single cell were $2.5 \mathrm{~W}$, $4.4 \mathrm{~W}, 6.9 \mathrm{~W}, 13.6 \mathrm{~W}$, respectively) .The temperature of the measured points in PCM and coupled system under the above conditions were measured. Then the average temperature of each measured point was calculated. The diagram of the temperature changed with time is shown in Figure 6.
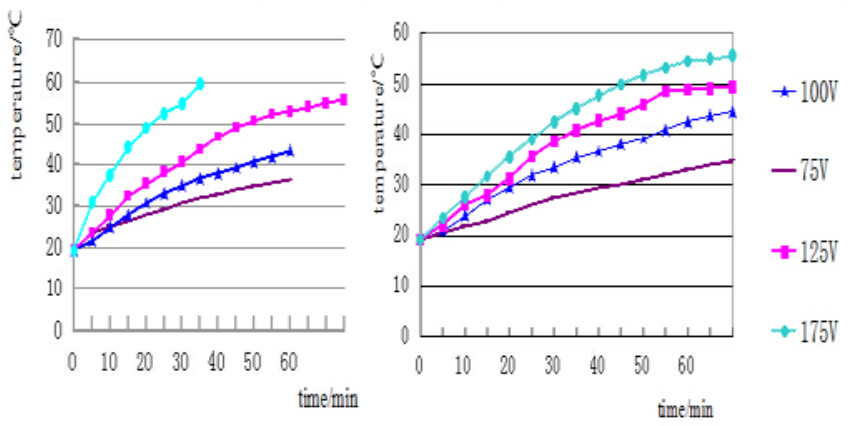

FIGURE VI. THE TEMPERATURE DIAGRAM OF PCM_(LEFT) AND COUPLED SYSTEM (RIGHT) UNDER DIFFERENT HEATING CONDITIONS
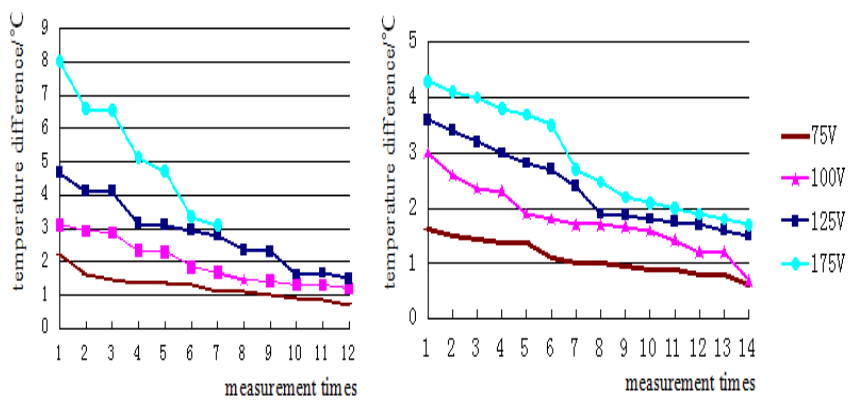

FIGURE VII. THE TEMPERATURE RISE SPEED DIAGRAM OF PCM (LEFT) AND COUPLED (RIGHT) SYSTEM.
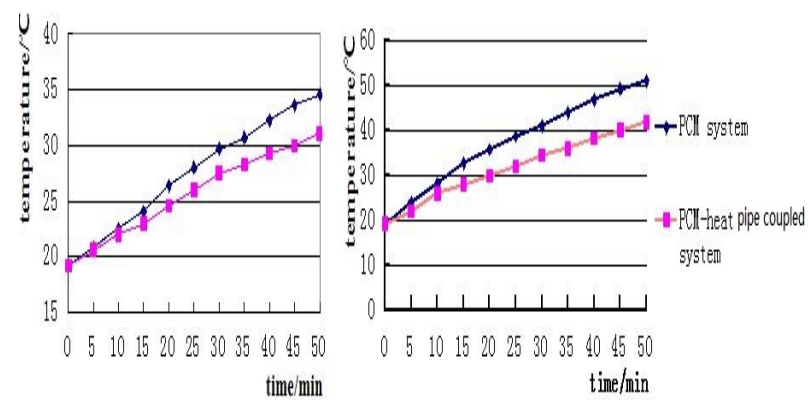

FIGURE VIII. TEMPERATURE COMPARISON IN DIFFERENT COOLING SYSTEM UNDER 75V (LEFT) AND 125V(RIGHT) HEATING CONDITION.

As can be seen from Figure 6, under the condition of 175V, the temperature in PCM system rise fast, which means that PCM passive cooling system, is not suitable for this condition. On the contrary, temperature rise of PCM-heat pipe coupled system is relatively slow, so the working parameter range of PCM-heat pipes coupled system is wider than that of PCM. The average temperature rise speed of each $5 \mathrm{~min}$ in different condition in PCM system and PCM-heat pipe coupled system is shown in Figure 7, and we can learn that the temperature rise speed is gradually lowered in both systems and the heat pipe's temperature rise speed is lower than PCM's. As we can see from Figure 8 , at $50 \mathrm{~min}$ time point, it is $4.8^{\circ} \mathrm{C}$ higher compared PCM system with PCM-heat pipe system in the condition of $75 \mathrm{~V}$, while it is $10^{\circ} \mathrm{C}$ higher in the condition of $125 \mathrm{~V}$, which means the greater power the condition is, the more obvious advantage of PCM-heat pipe coupled system is.

\section{CONCLUSION}

(1)The PCM-heat pipe coupled system can make a more uniform temperature distribution in the battery pack, which is good for its service life.

(2) The temperature rise speed of PCM-heat pipe coupled system is slower than PCM cooling system. So the former system has a superior performance on heat dissipation. Moreover, it can expand the parameter scope of application of power battery.

(3)The active cooling mode of PCM-heat pipe coupled system is capable of absorbing more heat, and its cooling effect is better than pure phase change material. In addition, 
the cooling system can meet the requirement of electric vehicle battery-pack's cooling need under normal condition.

\section{ACKNOWLEDGEMENT}

This study is supported by the Jilin University Students' Innovative Project, which I acknowledge with best thanks.

\section{REFERENCES}

[1] Schumann,Qingquan Chen,Fengchun Sun. Basis of hybrid electric vehicle[M]. Beijing: Beijing Institute of Technology Press, 2001.

[2] Chunhui Li, Research of EV's development status and trends, Auto Industry Research, 2005, 12(5): 44-46.

[3] Qingquan Chen,Fengchun Sun,Jiaguang Zhu. Modern electric vehicle technology [M]. Beijing: Beijing Institute of Technology Press, 2002.

[4] Yongge Luo, Ying Feng, Xiaochun He, Development prospects for hybrid electric vehicles[J]. Hubei College of Automotive Engineering, 2000, 14(1): 9-13.

[5] Pesaran A A, Battery thermal management in EV and HEV: Issues and Solutions[C], Advanced Automotive Battery Conference, Las Vegas, Nevada, February 6-8, 2001.

[6] Galvita V V, Semin G L, Belyaev V D, et al. Production of hydrogen from dimethyl ether[J]. Applied Catalysis A : General, 2001, 216 (1-2) 85-90.

[7] Haibo Chen, Xufeng Liu et al, Experimental Study on Cooling Vehicle Power Battery by Phase Change Materials[C],2014 20th National Conference of Engineering Thermophysics of Higher Education Institution Proceedings, Qingdao, China. 2014.5.2-5. 